\section{Each co-author should sign to reduce risk of fraud}

SIR - Although I am in favour of all efforts to reduce scientific fraud, I do not feel that the proposal made in your Editorial 'Who is accountable?' (Nature 450, 1; 2007) namely, for researchers to sign a policy statement - will have any real effect.

Researchers must already navigate numerous formalities during the publication process. Signing such statements could soon become so routine that they would not give it a second thought. During investigations into scientific misconduct, these signatures would not constitute evidence of anything. We already have rules about integrity and conduct; disciplinary committees gain no leverage by pointing to additional signatures on additional declarations.

I support the push for declarations that require careful thought on the part of each co-author. Once each co-author is required to describe his or her contribution and to sign a final description of the division of labour, then it will be clear who is responsible for any particular aspect of the work. Researchers can limit their liability to fraud charges only by limiting their claim to the paper's achievements.

Only by such an active process can investigators use these declarations as meaningful statements. Given the additional benefit of recording each researcher's contribution to impact, this system might warrant the extra burden.

Kevin Yager

Polymers Division, National Institute of Standards and Technology, 100 Bureau Drive, MS 8541, Gaithersburg,

Maryland 20899-8541, USA

Readers are welcome to comment at http:// blogs.nature.com/nautilus/2007/10/ accountability_of_co-authors.html

\section{Moon is the best witness to early Solar System history}

SIR - Nature usually recognizes emerging areas of scientific importance and adheres to high scientific and journalistic standards, so you are probably embarrassed by your amateurish and out-of-touch Editorial 'Because it's there' (Nature 450, 2; 2007). You remark "Although there are interesting scientific questions about the Moon, few, if any, are of the first order." This insults planetary scientists who have been working hard to understand the early history of our Solar System.

The Moon is recognized as the best available witness to 4.5 billion years of Solar System history; the early record is clearer and more complete there than on any other planetary body. Its importance is well documented in the recent report published by the National Research Council of the National Academies, The Scientific Context for Exploration of the Moon (http://books.nap.edu/catalog. php?record_id=11954).

Carle M. Pieters, George A. Paulikas National Research Council Committee on the Scientific Context for Exploration of the Moon, Washington DC, USA

\section{Modifying theories is the fabric of scientific progress}

SIR - Your News story 'Long-held theory is in danger of losing its nerve' (Nature 449, 124-125; 2007) discussed recent technical criticisms of work by Henri Korn, Don Faber and colleagues that was published in the early 1980s. Korn and his co-authors have replied to this News story in Correspondence ('One-vesicle hypothesis has been extensively discussed' Nature 449, 781; 2007).

I would like to add my view, as I find it disturbing not only that you publish suggestions of data fabrication, but also that you revive old allegations against Korn that have already been dismissed in 1989 and 2004.

Classical work by Bernard Katz and colleagues showed that neurotransmitter release is quantized at the neuromuscular junction. These early workers formulated a mathematical approach to investigate the statistics underlying neurotransmitter release, termed quantal analysis. There were two important parameters, the release probability, $p$, and $n$, which was interpreted as the number of available vesicles. Because $p$ was small and $n$ was larger, Poisson statistics seemed to be an adequate approximation to neurotransmitter release statistics. When quantal analysis was applied in the central nervous system, $n$ did not seem to be large any more and binomial statistics thus emerged as the model of choice.

This posed a problem regarding the biological interpretation of the parameter $n$, as it was small in relation to the number of vesicles. Korn, Faber and colleagues, guided by experiment and modelling, proposed that $n$ represents the number of synaptic contacts rather than the number of vesicles. This fundamental insight changed the way in which neuroscientists think about synaptic transmission.

Like every influential theory, this proposal has been extensively scrutinized and refined over the past quarter of a century. It turns out that the model parameters $n$ and $p$ have more complicated biological interpretations and are not stable over time or across synapses. In some systems, even the very concept of quantal transmission seems to be violated.

However, finding exceptions and modifications to scientific theories does not invalidate the theories or make them worthless. Rather, this is the very fabric of the scientific process. To instil a sense of scandal into this process degrades science and misleads the public about the scientific process.

Felix E. Schweizer

Department of Neurobiology, David Geffen School of Medicine, University of California at Los Angeles, 650 Charles E. Young Drive South, Los Angeles, California 90095-1763, USA

\section{Good thinking should not be wasted on bad ideas}

SIR - Your Editorial 'Watson's folly' (Nature 449,948 ; 2007) seemed to contradict itself. Appropriately, you censured Watson for his past and recent racist pronouncements, but with the same pen you chided organizations for cancelling his speaking engagements, scolding them because "science is about nothing if not openness and critical debate". But the issue at hand really has nothing to do with science. In the most forgiving light, it is social polemics, and in the worst it is simple racism.

Watson's actions may be viewed as folly by racists, but to moral individuals his words are an indecency. Not every social conjecture is a valid scientific hypothesis; and humanity should not waste good thinking on hateful, immoral ideas. Watson's admitted statements were not folly: they were reminders of the extensive obstacles that many peoples still face in their quest for equal opportunity in democratic societies.

The organizations that cancelled Watson's engagements are socially responsible. Those engagements were never planned as forums for debate of Watson's racist attitudes.

Decisive action by those organizations prevented any perception that his assault on human dignity was permissible.

James L. Sherley

Programs in Regenerative Biology and Cancer,

Boston Biomedical Research Institute,

Watertown, Massachusetts 02472, USA

Readers are welcome to comment at http://blogs.nature.com/news/ thegreatbeyond $/ 2007 / 10 /$ james_watsons race_row.html.

Contributions to Correspondence may be submitted to correspondence@nature.com. They should be no longer than $\mathbf{3 0 0}$ words, and ideally shorter. Published contributions are edited. 